\title{
REZIM BARU MONARKI THAILAND: ANTARA DARURAT MILITER DAN KESEJAHTERAAN SOSIAL DI WILAYAH SELATAN
}

\author{
Bayu Mitra A. Kusuma1, Theresia Octastefani2 ${ }^{2}$ \\ ${ }^{1}$ Fakultas Dakwah dan Komunikasi, Universitas Islam Negeri Sunan Kalijaga \\ email: bayu.kusuma@uin-suka.ac.id \\ ${ }^{2}$ Fakultas Ilmu Sosial dan Ilmu Politik, Universitas Gadjah Mada \\ email: theresiaoctastefani@ugm.ac.id
}

\begin{abstract}
Muslim communities in Southern Thailand have experienced in discrimination among in economic, social, and politics. This condition has even occurred in the last seven decades under King Bhumibol Adulyadej, who was known to be wise king. Basically, King Bhumibol as the head of state always stated that social welfare approace is the best way to solve the problem, but almost every Thai Prime Minister as the head of government unfortunately always uses a militaristic approach that triggers social resistance. Since King Bhumibol died, Thailand has faced with the potential crisis for two reasons. First, Maha Vajiralongkorn as a successor, he is considered have different charisma with his father because he is very glamorous and have controversial lifestyle. Secondly, the absence of King Bhumibol, who has been a counterweight to the state made the Thai military more often coups. This conditions give impact to Muslim communities in the South who always live with uncertainty condition with two possibilities. First, Muslim communities have a better life under the new monarchy regime with social welfare and humanity approaches. Secondly, the condition of the Muslim communities will remains stagnant under the controversial king with continued by martial law.
\end{abstract}

Keyword: regime; monarchy; military; social welfare.

\begin{abstract}
ABSTRAK
Masyarakat Muslim di Thailand Selatan masih kerap mengalami diskriminasi secara ekonomi, sosial, maupun politik. Kondisi tersebut bahkan terjadi dalam tujuh dekade terakhir di bawah Raja Bhumibol Adulyadej yang dikenal arif dan bijaksana. Pada dasarnya Raja Bhumibol sebagai kepala negara selalu menyerukan pendekatan kesejahteraan sosial untuk memecahkan masalah ini, tetapi hampir setiap perdana menteri Thailand sebagai kepala pemerintahan justru menggunakan pendekatan militeristik yang memicu resistensi sosial. Sejak Raja Bhumibol mangkat, Thailand menghadapi potensi krisis politik yang disebabkan oleh dua alasan. Pertama, Maha Vajiralongkorn sebagai suksesor dianggap memiliki kharisma yang sangat berbeda dengan ayahnya karena gaya hidup yang glamour dan kontroversial. Kedua, ketidakhadiran Raja Bhumibol yang selama ini menjadi penyeimbang negara membuat militer Thailand yang dikenal sering melakukan kudeta menjadi lebih bebas. Kondisi ini berdampak pada masyarakat Muslim di Selatan yang semakin menghadapi ketidakpastian. Berdasarkan hasil analisis penulis, ada dua kemungkinan yang berpotensi terjadi. Pertama, masyarakat Muslim mendapatkan kehidupan yang lebih baik di bawah rezim monarki yang baru dengan pendekatan kesejahteraan sosial dan kemanusiaan. Kedua, kondisi masyarakat Muslim masih mengalami stagnansi di bawah raja kontroversial dengan berlanjutnya darurat militer.
\end{abstract}

Kata Kunci: rezim; monarki; militer; kesejahteraan sosial. 


\section{PENDAHULUAN}

Thailand adalah sebuah negara Mainland Asia dengan mayoritas penduduk beragama Buddha Theravada, dimana agama Budha seakan-akan didefinisikan sebagai agama resmi negara. Meskipun pada dasarnya konstitusi Thailand sama sekali tidak menyebutkan agama resmi negara, namun pada kenyataannya kehidupan berbangsa dan bernegara didasarkan pada nilai-nilai Buddha. Atau dengan kata lain, secara de jure tidak ada agama resmi negara, tetapi secara de facto agama resmi negara adalah Buddha. Sementara sebagian populasi penduduk lainnya menganut Konfusianisme, Islam, dan lainnya. Meskipun di Thailand Islam adalah agama minoritas yang populasinya kurang dari lima persen dari total populasi negara tersebut, tetapi Islam di Thailand adalah minoritas yang tumbuh cepat dan merupakan minoritas terbesar setelah Konfusianisme (Aphornsuvan, 2003: 3). Populasi Muslim di Thailand hingga saat ini sebagian besar berada di wilayah selatan.

Sebagai negara yang bersifat multietnis, Thailand tak dapat menghindarkan diri dari terjadinya benturan antar kelompok massa. Benturan tersebut salah satunya disebabkan karena adanya hubungan asimetris antara kelompok minoritas dengan mayoritas. Akibatnya muncul berbagai konflik sosial bernuansa etnis dan agama yang tak kunjung padam. Fenomena tersebut hingga saat ini masih menjangkiti berbagai lini kehidupan. Masyarakat Muslim masih kerap mendapat tindakan diskriminatif oleh pemerintah, khususnya oleh perdana menteri dan rezim militer, dalam urusan sosial dan politik (Kusuma dan Octastefani, 2016: 34). Sampai hari ini mereka masih menghadapi diskriminasi yang kompleks, teror yang terus-menerus sehingga kehidupan sosial mereka sangat dikontrol oleh negara. Hal itu dapat dirasakan dari kehadiran militer yang masih mengakar dan membatasi kehidupan masyarakat di setiap sudut kota dan desa dengan adanya banyak sekali military check point atau pos pemeriksaan. Kondisi ini terus terjadi padahal Thailand dipimpin oleh seorang raja yang dikenal sangat bijaksana dan penuh kasih, Raja Bhumibol Adulyadej. Penduduk Thailand pada umumnya merasakan kehilangan dan kesedihan yang begitu mendalam ketika Raja Bhumibol meninggal dunia dua tahun silam.

Dalam konteks ini muncul sebuah paradok, bagaimana mungkin diskriminasi pada sebuah kelompok minoritas terjadi di bawah Raja yang terkenal bijak. Kondisi ini semakin tidak menentu ketika melihat putra mahkota yang menjadi suksesor ayahnya sebagai raja adalah sosok yang kontroversial dan glamor, Maha Vajiralongkorn. Berdasarkan penjelasan di atas, maka menjadi menarik untuk meneliti lebih lanjut bagaimana masa depan Masyarakat Muslim di Thailand Selatan di era rezim monarki baru. Apakah mereka akan disentuh dengan pendekatan kesejahteraan yang lebih manusiawi ataukah darurat militer kembali menjadi opsi yang diteruskan oleh raja baru.

\section{BHUMIBOL ADULYADEJ: SANG BAPAK BANGSA}

Sejak 9 Juni 1946, Bhumibol Adulyadej secara resmi naik tahta menjadi Raja Thailand untuk menggantikan posisi Raja Ananda Mahidol (Rama VIII), saudaranya yang meninggal secara misterius dengan luka tembak. Dia adalah raja kesembilan dari Dinasti Chakri. Meskipun pada saat dia naik tahta diwarnai oleh kontroversi terkait dengan kasus kematian saudaranya, tetapi di bawah kepemimpinan Bhumibol, ia mampu menjadi sosok pemimpin yang bijaksana dan memiliki hubungan dekat dengan rakyat Thailand. Itu membuat rakyat Thailand mencintai rajanya karena dia mengabdikan hidupnya untuk bekerja keras meningkatkan kesejahteraan sosial ekonomi bagi semua warga Thailand, menjaga stabilitas politik-pemerintah, dan sejarah positif lainnya. 
Slogan Long Live the King merupakan salah satu cara untuk menunjukkan bagaimana rakyat benar-benar mencintai rajanya. Namun, meskipun di negaranya Raja Bhumibol begitu dihormati, tetapi di sisi lain, biografi negatif Raja Bhumibol pernah ditulis oleh seorang jurnalis Amerika bernama Paul M. Handley. Dalam bukunya, dengan judul The King Never Smiles: A Biography of Thailand's Bhumibol Adulyadej (2006) menggambarkan narasi negatif dan kritik terhadap kehidupan pribadi dan kepemimpinan Bhumibol selama 60 tahun sebagai Raja Thailand. Dalam bukunya yang kontroversial, Handley menggambarkan Bhumibol sebagai orang yang sangat politis, otokratis, brutal, dan bahkan diduga terlibat korupsi. Ini sangat kontras dengan citra positifnya sebagai Raja yang dermawan dan egaliter.

Namun di luar itu, faktanya sampai akhir hidupnya Raja Bhumibol sangat dihormati dan menunjukkan jiwa yang welas asih. Sejarah Thailand mencatat bahwa dalam menghadapi pergolakan di Selatan negara dimana mayoritas penduduknya beragama Islam, Raja Bhumibol lebih suka mempromosikan pendekatan sosial dan kesejahteraan (Kusuma, 2017: 43). Meskipun dalam implementasinya di bawah kendali perdana menteri Thaksin Sinawatra pendekatan tersebut malah diubah menjadi darurat militer. Munculnya kembali pemberontakan Thailand Selatan selama Era Thaksin (2001-2006), ditandai dengan pemboman, penculikan, pemenggalan kepala, dan penembakan (Yusuf, 2009: 48). Hingga kini, darurat militer masih berlangsung dan telah sangat mempengaruhi kondisi sosial, ekonomi dan psikologis Kelompok Muslim di Thailand Selatan. Selain itu, Thaksin juga pernah mencetuskan pernyataan kontroversial bahwa orang Thailand adalah penganut Buddha; jika mereka bukan penganut Buddha, maka mereka harus menggunakan bahasa Thailand. Jadi menurutnya jika seseorang memeluk Islam, orang itu hanya bisa disebut Thailand hanya jika mereka menggunakan bahasa Thailand (Kusuma, 2016: 11). Tentu saja, kondisi ini sangat sulit bagi Muslim Melayu.

Pada 13 Oktober 2016 pukul 15.42, Raja Bhumibol Adulyadej atau Rama IX wafat pada usia 88 tahun. Dia menjadi raja dengan masa berkuasa terpanjang di dunia. Dia meninggal dua setengah tahun setelah kudeta militer Mei 2017 yang dipimpin oleh Perdana Menteri saat ini, Jenderal Prayuth Chan-o-cha, yang menggulingkan pemerintahan terpilih Yingluck Shinawatra, adik perempuan mantan Perdana Menteri Thaksin, yang juga digulingkan dalam sebuah kudeta pada bulan September 2006 (Jackson, 2017: 13). Hingga saat ini kematian Raja Bhumibol masih membawa duka dan kesedihan yang mendalam kepada orang-orang Thailand. McCargo (2012: 641) menyatakan bahwa politik monastik di Thailand adalah cermin dari politik sekuler negara itu, yang ditandai oleh perpecahan yang mendalam dan ketidakpastian tentang masa depan. Sebagai pengganti raja, penerus takhta yang telah disiapkan adalah Pangeran Maha Vajiralongkorn. Namun sejauh ini, identitas Maha Vajiralongkorn cukup misterius.

\section{VAJIRALONGKORN: SUKSESOR KONTROVERSIAL}

Maha Vajiralongkorn Bodindradebayavarangkun adalah anak laki-laki satusatunya Raja Bhumibol dan Ratu Sirikit. Masa depan Kerajaan Thailand menjadi tanggung jawab Vajiralongkorn. Dalam proses transisi kekuasaan ini, rakyat Thailand dibayangi oleh ketidakpastian karena Vajiralongkorn tidak seperti ayahnya, raja baru dan pemerintahan baru kemungkinan akan mengeja perubahan pada konfigurasi dan dinamika politik Thailand, perubahan penjaga dimana beberapa mantan penasihat di bawah Raja Bhumibol telah dan akan digantikan oleh preferensi Raja Maha Vajiralongkorn (Pongsudhirak, 2017: 100). Farelly (2017: 5) menyatakan bahwa dengan Raja Vajiralongkorn naik tahta, Thailand sekali lagi akan memiliki raja yang perlu lebih aktif di depan umum. 
Dua tahun yang lalu, tabloid Jerman, Bild, memposting cerita pendek tentang Pangeran Vajiralongkorn. Bukan sekedar rumor, tapi gambar Pangeran terpotret jelas hingga menjadi pembicaraan. Pesawat Boeing 737 yang membawa Pangeran Vajiralongkorn dan selirnya, Suthida Ayudhaya, bersama dengan sekitar tiga puluh penjaga, mendarat di Bandara Muenchen, Jerman. Begitu pintu terbuka, Vajiralongkorn turun dan disambut oleh para kru dengan hormat. Tidak seperti biasanya, Pangeran Vajiralongkorn hanya mengenakan baju mini singlet yang tidak bisa menutupi bagian atas tubuhnya (Pradityo, 2017). Usia Pangeran Vajiralongkorn sebenarnya tidak lagi muda, yaitu 64 tahun dan setidaknya memiliki tujuh anak. Tidak seperti ayahnya, Raja Bhumibol Adulyadej, yang mempertahankan citra di depan rakyat. Vajiralongkorn, gaya hidup dan tindakan eksentriknya sering memancing gosip. Namun di Thailand, perilakunya hanya menjadi bisikan karena pembicaraan buruk tentang keluarga Raja bisa berakhir di penjara. Petualangan cinta Putra Mahkota dengan banyak wanita memang telah menjadi rahasia umum. Dengan rekam jejak negatif itu, tidak mengherankan bahwa beberapa elit dan rakyat Thailand tidak yakin bahwa Pangeran Vajiralongkorn dapat dihormati dan menjadi pemersatu Kerajaan Thailand seperti ayahnya. Reputasi Pangeran Vajiralongkorn tidak seberapa cemerlang. Bahkan popularitas penerus Dinasti Chakri masih jauh dari saudara perempuannya, Putri Maha Chakri Sirindhorn, yang sangat cerdas dan aktif dalam kegiatan sosial.

Thailand dikenal memiliki situasi politik yang kompleks. Sekitar sepuluh kali kudeta militer dan pergantian Perdana Menteri terjadi di Thailand selama Bhumibol menjabat sebagai raja. Sosok Bhumibol, yang dikenal sebagai pemersatu negara, diharapkan akan dilanjutkan oleh Vajiralongkorn. Sebagai seorang pria dengan pendidikan militer, pelatihan, dan pengalaman, ia diharapkan siap dan mampu membela bangsa. Untuk meningkatkan rekam jejak positifnya, Vajiralongkorn mulai aktif dalam berbagai kegiatan publik. Pada 2016, Dia memimpin ribuan pengendara sepeda di jalan-jalan Bangkok, dalam dua acara olahraga yang diadakan untuk menghormati orang tuanya. Dia berupaya menggambarkan dirinya sebagai anak yang berbakti dan penuh kasih sayang kepada orang tua. Di tengah situasi transisi yang kontroversial ini, bagaimana dengan masa depan komunitas Muslim di bawah era Vajiralongkorn?

\section{HARAPAN PADA REZIM MONARKI BARU}

Penelitian terkait relasi Islam dan negara di Thailand hampir selalu dipandang dari perspektif konflik serta nyaris selalu berkutat pada wilayah Pattani, Yala, dan Narathiwat. Meskipun sebenarnya terlalu sempit rasanya bila menggambarkan Islam di Thailand hanya dari tiga provinsi tersebut, karena dalam realitanya Muslim di Thailand telah menyebar dan berdiaspora di berbagai wilayah. Mereka mampu beradaptasi dengan tuntutan zaman, berkompromi dengan pengaruh global, dan membentuk identitas baru tanpa harus meninggalkan keyakinan dan identitas asal mereka (Rozaki, Kusuma, dan Faiz, 2019: 107). Salah satu provinsi yang identik dengan karakteristik tersebut adalah Nakhon Si Thammarat, sebuah provinsi yang secara geografis letaknya tidak jauh dari Pattani. Namun riset mengenail Pattani dan sekitarnya tetaplah menarik untuk terus digali karena faktanya hingga saat ini militer masih berada di setiap sudut wilayah selatan.

Masalah-masalah di Thailand Selatan adalah hasil dari pengabaian ekonomi selama beberapa dekade; kurangnya kesempatan kerja bagi Muslim lokal di sektor publik dan swasta; ketidakpekaan budaya birokrasi; dan tidak ada pengakuan keragaman agama, bahasa, dan budaya dalam pemerintahan Thailand (Yusuf, 2009: 54). Pemerintah Thailand harus memiliki solusi alternatif yang lebih besar untuk memenuhi tuntutan populasi Muslim lokal di Thailand Selatan. Nurakkate (2012: 4) menyatakan bahwa pemberontakan 
di Thailand Selatan pada dasarnya rumit, dan tidak ada faktor tunggal yang dapat menjelaskan mengapa kekerasan kembali terjadi di Thailand Selatan pada tahun 2004. Sudah satu dekade sejak pecahnya salah satu pemberontakan paling serius di Asia, konflik antara Muslim Melayu dan negara Thailand di Thailand Selatan (McCargo, 2017: 1). Dengan masalah rumit di Thailand dan ditambah dengan gaya hidup Vajiralongkorn, banyak yang berpikir bahwa masalahnya akan lebih buruk.

Namun dibalik gaya hidup yang kontroversial, ternyata ada sisi lain dari Raja Maha Vajiralongkorn yang belum banyak terungkap. Dia cukup dekat dan memberikan perhatian kepada umat Islam di Thailand. Menurut pandangan sejumlah akademisi yang ditemui oleh peneliti selama di Thailand Selatan, mayoritas dari mereka menyatakan bahwa selama masa ini Pangeran Mahkota Vajiralongkorn telah lebih memperhatikan komunitas Muslim. Selain aktif terlibat dengan akademisi Muslim di Selatan, Vajiralongkorn juga dikenal dekat dengan dewan Islam setempat. Bahkan Vajiralongkorn hadir secara langsung di Pattani tidak berselang lama setelah dia dinobatkan menjadi raja.

Sejauh ini pemerintah Thailand identik dengan kekerasan ketika menghadapi perlawanan sosial Muslim di Selatan. Rupanya, ini adalah salah satu yang ingin diubah oleh raja baru. Sebagai contoh, pada tahun 2016, pengguna media sosial Youtube bernama Qistina Balqis mengunggah sebuah tayangan video yang menggambarkan Maha Vajiralongkorn mengangkat tangan dan bergumam dalam upacara shalawatan di Selatan. Meskipun tidak ada konfirmasi atau klarifikasi dari Royal Palace tentang video ini, penghormatan terhadap kepercayaan minoritas adalah refleksi kemanusiaan yang dihargai. Sikap hormat ini diharapkan membawa angin segar bagi minoritas Muslim di Thailand yang sering merasa tertindas. Karena itu, naiknya Vajiralongkorn lebih diterima dengan baik oleh umat Islam di Selatan dan diharapkan membawa angin perubahan bagi kehidupan sosial di sana. Harapannya ke depan darurat militer segera diakhiri dan kesejahteraan sosial menjadi pendekatan yang permanen.

\section{KESIMPULAN}

Bhumibol Adulyadej naik tahta disertai dengan kontroversi mengenai kasus kematian saudaranya, tetapi ia mampu menunjukkan bahwa ia adalah seorang pemimpin yang dekat dengan rakyatnya, sehingga ia sangat dicintai. Meskipun di negaranya Raja Bhumibol begitu dihormati, tetapi di sisi lain, biografinya juga ditulis dengan penggambaran negatif bahwa Bhumibol adalah seorang yang sangat politis, otokratis, brutal dan bahkan diduga terlibat korupsi. Namun di luar itu, faktanya menunjukkan bahwa sampai akhir hidupnya Raja Bhumibol sangat dihormati dan menunjukkan jiwa welas asih. Hal tersebut dibuktikan dengan pendekatan sosial dan kesejahteraan yang ia inginkan untuk mengatasi permasalahan di Thailand Selatan, meskipun dalam implementasinya di bawah kendali Perdana Menteri Thaksin Sinawatra pendekatan tersebut justru menjadi paradoks karena berubah menjadi darurat militer.

Ketika Bhumibol mangkat, penerus takhta adalah tokoh kontroversial, Pangeran Maha Vajiralongkorn. Gaya hidup sang pangeran sering menjadi perbincangan. Mulai dari fasilitas mewah sampai dengan romansa yang diwarnai dengan pernikahan dan perceraian di kalangan selebritis. Namun di balik gaya hidup yang kontroversial tersebut, ternyata dia cukup dekat dan memberikan perhatian kepada umat Islam di Thailand. Selain aktif terlibat dengan kegiatan para akademisi Muslim di Selatan, Vajiralongkorn juga dikenal dekat dengan dewan Islam setempat dan bersedia menghormati agama dan budaya minoritas lokal. Ia ingin mengubah pola kekerasan yang selama ini identik dengan penanganan konflik di Selatan. Karenanya, naiknya Vajiralongkorn sebagai raja lebih 
diterima dengan baik oleh umat Islam di Selatan dan diharapkan dapat mencegah munculnya konflik yang lebih besar.

\section{APRESIASI}

Versi awal dari naskah ini telah dipresentasikan di Diskusi Bulanan KSM Defensia yang diselenggarakan oleh Program Studi Hubungan Internasional, Fakultas Ilmu Sosial dan Ilmu Politik, Universitas Pembangunan Nasional "Veteran" Yogyakarta pada tanggal 23 Februari 2019.

\section{DAFTAR RUJUKAN}

Aphornsuvan, T. (2003). History and Politics of the Muslim in Thailand. Bangkok: Thammasat University.

Farrelly, N. (2017). Thailand's Triple Threat. Sydney: Lowy Institute for International Policy.

Handley, P. M. (2006). The King Never Smiles: A Biography of Thailand's Bhumibol Adulyadej. New Heaven: Yale University Press.

Jackson, P. A. (2017). Grateful Son, A Military King: Thai Media Accounts of the Accession of Rama $X$ to the Throne. Singapore: ISEAS-Yusof Ishak Institute.

Kusuma, B. M. A. (2017). "Islam, Asymmetric Policy, and Social Conflict: The State's Role as a Root of Radicalism in the Philippines and Thailand". IKAT: The Indonesian Journal of Southeast Asian Studies Vol. 1 No. 1, 33-46.

(2016). "Masyarakat Muslim Thailand dan Dampak Psikologis Kebijakan Asimilasi Budaya". Hisbah: Jurnal Bimbingan dan Konseling Islam Vol. 13 No. 1, 109-120. dan Octastefani, T. (2016). "Patani United Liberation Organization: From Jihad to Local Politics Movement”. The Indonesian Journal of Public Administration Vol. 2 No. 1, 33-44.

McCargo, D. (2017). Southern Thailand: From Conflict to Negotiations? Sydney: Lowy Institute for International Policy.

(2012). "The Changing Politics of Thailand's Buddhist Order". Critical Asian Studies Vol. 44 No. 4, 627-642.

Nurakkate, C. (2012), "The Conflict in Southern Thailand". Shedden Papers, March Edition, 1-18.

Pongsudhirak, T. (2017). "Thailand After King Bhumibol: Foreign and Security Policy Implications". Security Outlook of the Asia Pacific Countries and Its Implications for the Defense Sector of National Institute for Defense Studies Research Series, 15, 5768.

Pradityo, S. (2017). Intermeso: Takhta untuk Pangeran Bengal. Diakses melalui link https://x.detik.com/detail/intermeso/20161014/Takhta-untuk-PangeranBengal/index.php pada 2 Agustus 2018.

Rozaki, A., Kusuma, B. M. A, dan Faiz, A. A. (2019). "Political Economy of the Muslim Middle Class in Southeast Asia: Religious Expression Trajectories in Indonesia, Malaysia, and Thailand". IKAT: The Indonesian Journal of Southeast Asian Studies Vol. 3 No. 1, 95-118.

Yusuf, I. (2009). "Ethnoreligious and Political Dimensions of the Southern Thailand Conflict". Pandya, A. \& Laipson, E. (ed). Islam and Politics: Renewal and Resistance in the Muslim World. Washington: The Henry Stimson Center. 